\title{
Impact of E-Commerce on Organization Performance: Evidence from Banking Sector of Pakistan
}

\author{
Muhammad Mehtab Azeem ${ }^{1}$, Akin Marsap ${ }^{1} \&$ Abdul Haseeb Jilani ${ }^{2}$ \\ ${ }^{1}$ Department of Economics and administrative Science, Istanbul Aydin University, Turkey \\ 2 Department of Business Administration, University of Central Punjab, Lahore, Pakistan \\ Correspondence: Muhammad Mehtab Azeem, Istanbul Aydin University \& Francois Rabelais University, MBA, \\ Turkey. Tel: 92-46-251-0151. E-mail: mehtabazeem@yahoo.com
}

Received: May 22, 2014

doi:10.5539/ijef.v7n2p303
Accepted: December 20, 2014

Online Published: January 25, 2015

URL: http://dx.doi.org/10.5539/ijef.v7n2p303

\begin{abstract}
In the recent years, E-banking is one of the most important revolutions in the banking sector of Pakistan. This study measures the impact of e commerce (B2B, B2C, C2C) on organization performance (Business operation, Job performance, Customer satisfaction). The sample of this research is collected from the banking sector of Pakistan by using 50 samples filling online from the period 2012 to 2013 . Results show that there is positive relationship between e-commerce and organization performance and by implementing e-commerce; organizations improve its performance in terms of business operations, job performance and customer satisfaction. Major research has been withdrawn from MBA thesis subject Impact of foreign banks on domestic banks businesses.
\end{abstract}

Keywords: electronic commerce, organization performance, business to business, business to customer, customer to customer

\section{Introduction}

The innovative use of technology brought huge impact on banking sector and creates new interactive ways through which customers can interact with banks. The development of electronic channels changed the natures of financial services delivered to customer by the widely use of electronic banking technologies (ATM, Mobile banking, online banking, electronic fund transfer and direct deposit). Pakistani banking sector has seen grown over the past few year. According to the State Bank of Pakistan report, the electronic banking transaction's volume was 31.5 million during 2nd Quarter of 2007-2008 fiscal years in which Automated Teller Machine transactions were 16.5 million and the volume of other E banking channel's transactions has been 4.8 million in the same quarter. During quarter 4 in same fiscal year, E banking transaction reaches to 34.0 million which clearly shows the Electronics Banking adoption trend in Pakistan. During past few years Electronic-banking has gain important place in the organizations.

Banks are accretion actors in the economy of any country. The well-developed banking sector of Pakistan consist of broad range of institutions starts from central bank and includes many development financial institutions and most common commercial banks to fulfill the requirement of multiple sectors. Currently in Pakistan four commercial banks are operating which includes: foreign, private, privatized, and nationalized commercial banks etc. In Pakistan State Bank of Pakistan (SBP) is the monetary body for all banking sector because Banking companies' ordinance, 1962 empowers the Central bank (SBP) for supervision and regulation of these financial institutions. During the last five decades Pakistani banking sector passed through various stages include: nationalization in the seventies and privatization in nineties.

E-Commerce is to facilitate and implement business processes through the use of telecommunications network means i.e. Internet. (Delone \& Mclean, 2004). Due to technological advancements many businesses are capable to perform the functions of e commerce more easily and efficiently till now and become more competitive by using the means of telecommunication networks. In many businesses, they use different types of models based on their nature and operations. The different types of electronic commerce includes Business to business, Business to consumer and Consumer to consumer (Zwaas, 2003). 


\section{Literature Review}

\subsection{E-Commerce}

E-commerce is a concept which means that the sales purchase or exchange of goods \& services or information is by using a computer network, including the Internet. With respect to communication it is to provide information, services, payment and product using computer networks, telephone networks and other electronic means (Galati, 2010). There are three type of e commerce i.e. business to business, business to customer and customer to customer.

According to Watson et al. (1999), electronic commerce is the source of improvement in organizational performance by using computer networks. Turban et al. (2000) defines E commerce as the process of buying \& selling or exchanging of products or services and information via computer networks includes the Internet. In electronic commerce organization use electronic tools such as file transfer, fax, video conferencing, EDI and file transfer etc. In the past, trade is carry on with the physical presence of buyer and sellers but now a day with the technological advancement, it is not necessary for both to appear physically at the market place. The invention of telecommunication network means i.e. internet, web technologies and other electronic devices makes easy the business as well as facilitate the both (business and customers). Buyer of product and services can online order the product by using internet without physically appearing to that shop or office and seller deliver that product according to the order. Through this buyer save its time as well as transportation cost and seller build a strong relationship with the customer and got the list of customers as well as manage the inventory.

\subsection{Organization Performance}

OP mainly focus on three areas of firm's outcome i.e. Customer satisfaction, Product market performance and Product services quality Richard et al. (2009). Organization performance can be measured through efficiency and effectiveness (Robins et al., 2009).

An organization is efficient if it is cost and time effective (Bardhan, 2005). The scope of this research is to measure the organization performance i.e. business operation, customer satisfaction and job performance in the banking sector of Pakistan.

In customer satisfaction: customer evaluate the product or services on the basis of expectation from that product or services which satisfied or not. Business operation involves activities that are involved in business operations to maximize the firm's value. Job performance refers to the accomplishment of tasks and responsibilities assigned to the individual or employee on job place.

\section{Research Model}

In this research organization performance is our dependent variable and e commerce as independent variable. Dependent variable (organization performance) is divided into business operation, customer satisfaction and job performance. E-commerce is classified into $\mathrm{B} 2 \mathrm{~B}, \mathrm{~B} 2 \mathrm{C}$ and $\mathrm{C} 2 \mathrm{C}$. There is significant relationship between electronic commerce and organization performance. In this research we will find the relationship between electronic commerce and organizational performance. By adopting the e-commerce practices the organizational performance increases. The organizations that implement e-commerce have tremendous advantage in quality, cost, profit, and employee motivation (Singh, 2002). It is observed that by adopting e-commerce the organizational performance like profit, market share, and customer services improved. And we see significant improvement in organization's practices regarding marketing, finance, manufacturing, selling and administration (Richard et al., 2009). There was a significant relationship between the E-commerce application and OP in the banking sector of Pakistan. Those organizations which do not use e commerce application may have disadvantage relative to their competitors.

Electronic commerce has dramatically affected the operations of the business and companies spend a large portion of investment in e commerce applications which may lead toward the organizational achievements. Rapidly adoption of Electronic commerce applications like internet, electronic mail, video conferencing and fax changed the nature of the business. These applications lead towards the substantial changes in traditional businesses and companies. Many firms are trying to understand and measure the electronic commerce so that they can do wise decisions regarding the operations of the firm (Singh, 2002). Electronic commerce significantly affects the organizational performance and efficiency. Businesses and firms are using electronic commerce to increase the overall operational efficiency of the firm. Emergence of electronic commerce has dramatically affect the overall organizational effectiveness and companies get competitive advantage through adopting the electronic commerce applications.

In many businesses there is strong need to share the information with general public based on the nature of 
business so at that time if information is not accessible to everyone then business bears the loss or miss the opportunity that it can achieve. E-commerce has shortened these gaps and makes information accessible to everyone and strengthens the relationship between business and customers as well. It can also make easy the transactions between the business and customers through providing the online services i.e. fund transfer, billing, cash withdrawal and many other etc.

In the past, banking is on the manual basis. There are many people required to do one task and consume too much time and to keep record of past data is the big problem for the organizations. So efficiency of workers decreased after some time and results in the form of slow productivity or business processes. There is strong need arises for the most efficient and effective system that can make these tasks more easy and accurate so World Wide Web (WWW) create a boom in the banking sector and totally change the nature of doing banking, many manual tasks are replaced by computer technology and make tasks easy, accurate and with small employs or workers.

The reliability of the work is also increased because in a manual work there are maximum error chances but one can do that task with the help of computer software then can get more accurate and reliable results. Large companies are using electronic commerce to make their business healthy and strong but they have to first invest a healthy amount in the implementation of adopting electronic commerce. In recent years people are switching from traditional ways of business to the modern one through electronic commerce.

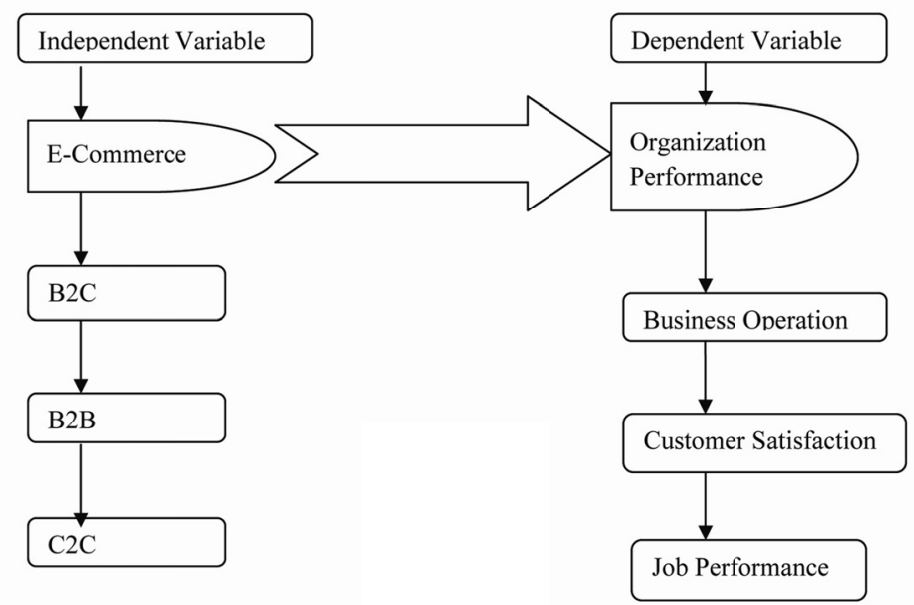

Figure 1. Model diagram

Table 1. Variables and measurement

\begin{tabular}{llll}
\hline & Scale name & Alpha value & No. of items \\
\hline 1 & Business Operation & 0.707 & 5 \\
2 & Customer Satisfaction & 0.737 & 5 \\
3 & Job Performance & 0.711 & 5 \\
4 & B2c & .727 & 8 \\
5 & B2b & .726 & 4 \\
6 & C2c & .758 & 3 \\
\hline
\end{tabular}

Research hypothesis:

H1: There is a positive relationship between e-commerce and organizational performance.

$\mathrm{H} 2$ : There is positive relationship between e commerce and business operation.

H3: There is positive relation between e commerce and customer satisfaction.

H4: There is positive relation between e commerce and job performance.

Business Operation consisting of 5 items and the reliability is 0.707 . After performing factor analysis of Customer Satisfaction consisting of 5 items, 1 item have been excluded in order to ensure the reliability 0.737. 
After performing factor analysis of Job Performance consisting of 5 items, 1 item have been excluded in order to ensure the reliability 0.711 . After performing factor analysis of $\mathrm{B} 2 \mathrm{C}$ consisting of 8 items, 3 item have been excluded in order to ensure the reliability 0.727 . Business 2 business consisting of 3 and the reliability is 0.726 . After performing factor analysis of $\mathrm{C} 2 \mathrm{C}$ consisting of 3 items and the reliability is 0.758 .

Business operation: This is dependent variable that includes those activities which involve in business operations to maximize the firm's value. We own develop 5 items to measures this variable. The measure is reported to have convergent and discriminate validity and Cronbach's alpha for the five items for this sample was 0.707 .

Customer satisfaction: This is dependent variable in which customer evaluate the product or services on the basis of expectation from that product or services which satisfied or not. We developed five items to measures this variable. The measure is reported to have convergent and discriminate validity and Cronbach's alpha for the five items for this sample was 0.737 .

Job performance: This is dependent variable that refers to the accomplishment of tasks and responsibilities assigned to the individual or employee on job place. We developed five items to measures this variable. The measure is reported to have convergent and discriminate validity and Cronbach's alpha for the three items for this sample was 0.711 .

Business to customer: $\mathrm{B} 2 \mathrm{C}$ is independent variable, In b2c companies/businesses conduct transaction with consumer through electronic channels, We developed eight items to measures this variable. The measure is reported to have convergent and discriminate validity and Cronbach's alpha for the eight items for this sample was 0.727 .

Business to Business: $\mathrm{B} 2 \mathrm{~B}$ is independent variable. It is web enabled applications through which inter-organizational coordination business partner's relationship can be improved. We developed three items to measures this variable, The measure is reported to have convergent and discriminate validity and Cronbach's alpha for the three items for this sample was 0.726 .

Customer to customer: $\mathrm{C} 2 \mathrm{C}$ is independent variable. In c2c e commerce, person to person transaction occurs where individual can buy \& sell or send \& receive money online to other consumer. We developed three items to measures this variable, the measure is reported to have convergent and discriminate validity and Cronbach's alpha for the three items for this sample was 0.758 .

\section{Data Collection}

Questionnaire is used as a tool to conduct a survey in the city of Lahore Pakistan because it is second largest city in the country as with rich of all businesses and having almost all bank branches. The sampling technique which used in this research is probability sampling for a selection criterion.

In this research the participants was manger and operation manager from those commercial banks which are operating in Lahore city. Out of 50 questionnaires which are sent through mail 23 were returned which shows $46 \%$ response rate from the respondents and 80 questionnaires are filled directly from the mangers \& operation manager through which 78 are used in this research.

Table 2. Gender

\begin{tabular}{cccccc}
\hline & & Frequency & Percent & Valid Percent & Cumulative Percent \\
\hline \multirow{4}{*}{ Valid } & Male & 77 & 76.2 & 76.2 & 76.2 \\
& Female & 24 & 23.8 & 23.8 & 100.0 \\
& Total & 101 & 100.0 & 100.0 & \\
\hline
\end{tabular}

Table 3. Position in the organization

\begin{tabular}{cccccc}
\hline & & Frequency & Percent & Valid Percent & Cumulative Percent \\
\hline \multirow{4}{*}{ Valid } & Middle management & 64 & 63.4 & 63.4 & 63.4 \\
& Upper management & 37 & 36.6 & 36.6 & 100.0 \\
& Total & 101 & 100.0 & 100.0 & \\
\hline
\end{tabular}




\section{Research Findings}

\subsection{Correlation Analysis}

Table 4. Correlations

\begin{tabular}{|c|c|c|c|c|c|c|}
\hline & & $\begin{array}{c}\text { Finalorgper } \\
\text { formance }\end{array}$ & Ecommerce & C.satisfaction & BOPR & FINLJOBPER \\
\hline \multirow{3}{*}{$\begin{array}{c}\text { Finalorgper } \\
\text { formance }\end{array}$} & Pearson Correlation & 1 & $.541^{* *}$ & $.355^{* *}$ & $.911^{* *}$ & $.909^{* *}$ \\
\hline & Sig. (2-tailed) & & .000 & .000 & .000 & .000 \\
\hline & $\mathrm{N}$ & 101 & 101 & 101 & 101 & 101 \\
\hline \multirow{3}{*}{ Ecommerce } & Pearson Correlation & $.541^{* *}$ & 1 & .103 & $.503^{* *}$ & $.553^{* *}$ \\
\hline & Sig. (2-tailed) & .000 & & .306 & .000 & .000 \\
\hline & $\mathrm{N}$ & 101 & 101 & 101 & 101 & 101 \\
\hline \multirow{3}{*}{ C.satisfaction } & Pearson Correlation & $.355^{* *}$ & .103 & 1 & -.034 & -.043 \\
\hline & Sig. (2-tailed) & .000 & .306 & & .738 & .670 \\
\hline & $\mathrm{N}$ & 101 & 101 & 101 & 101 & 101 \\
\hline \multirow{3}{*}{ BOPR } & Pearson Correlation & $.911^{* *}$ & $.503^{* *}$ & -.034 & 1 & $.955^{* *}$ \\
\hline & Sig. (2-tailed) & .000 & .000 & .738 & & .000 \\
\hline & $\mathrm{N}$ & 101 & 101 & 101 & 101 & 101 \\
\hline \multirow{3}{*}{ FINLJOBPER } & Pearson Correlation & $.909^{* *}$ & $.553^{* *}$ & -.043 & $.955^{* *}$ & 1 \\
\hline & Sig. (2-tailed) & .000 & .000 & .670 & .000 & \\
\hline & $\mathrm{N}$ & 101 & 101 & 101 & 101 & 101 \\
\hline
\end{tabular}

Note. **. Correlation is significant at the 0.01 level (2-tailed).

Each hypothesis was then tested. The correlation matrix provided the answer to the first four hypotheses. The first hypothesis stated that there is positive correlation between e commerce organizational performances. The positive correlation of $0.54(\mathrm{p}<0.001)$ between the e commerce and organization performance substantiates this hypothesis.

The second hypothesis stated that if banks adopt e-commerce application then the business operations would improve. The positive correlation of $0.503(\mathrm{p}<0.001)$ between the ecommerce and business operation substantiates this hypothesis.

The third hypothesis stated that if banks adopt e commerce applications then it does not affect the customer satisfaction because there is weak correlation between e-commerce and customer satisfaction. The correlation of $0.103(\mathrm{p}<0.001)$ between the e commerce and customer satisfaction substantiates this hypothesis.

The fourth hypothesis stated that the e commerce has positive correlation with job performance. The correlation of $0.553(\mathrm{p}<0.001)$ between the e commerce and job performance substantiates this hypothesis.

\subsection{Regression Analysis}

Ecommerce is regressed against the organization performance. The result which is shown in table D Indicate that this hypothesis is also substantiated. That is, the $\mathrm{R}$ square value of 0.563 at a significant level of $\mathrm{P}<0.001$, with $\mathrm{df}(3)$, confirms that $56 \%$ of the variance in organization performance is significantly explained by the three independent variable i.e.b2b,b2c and $\mathrm{c} 2 \mathrm{c}$. This shows the overall strength of association between organizational performance and e-commerce applications e.g. B2B, B2C and C2C.

Table 5. Regression model

\begin{tabular}{|c|c|c|c|c|}
\hline \multicolumn{5}{|c|}{ 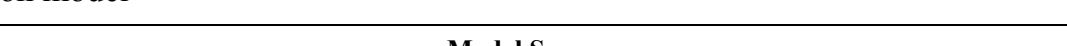 } \\
\hline $\sin$ & 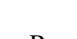 & 1 & el summary & $a_{0}$ \\
\hline 100 & $\mathrm{~K}$ & Squai & ea $\mathrm{R}:$ & ror the \\
\hline
\end{tabular}

Note. a. Predictors: (Constant), C2Customer, Busines2Bu, Busines2C. 
Table 6. ANOVA $^{\mathrm{b}}$

\begin{tabular}{ccccccc}
\hline & Model & Sum of Squares & df & Mean Square & F & Sig. \\
\hline \multirow{2}{*}{1} & Regression & 9.879 & 3 & 3.293 & .683 & \\
& Residual & 7.663 & 97 & .079 & & \\
& Total & 17.543 & 100 & & \\
\hline
\end{tabular}

Note. a. Predictors: (Constant), C2Customer, Busines2Bu, Busines2C.

b. Dependent Variable: FINALORGPERFORMANCE.

Table 7. Esimated regression parametres

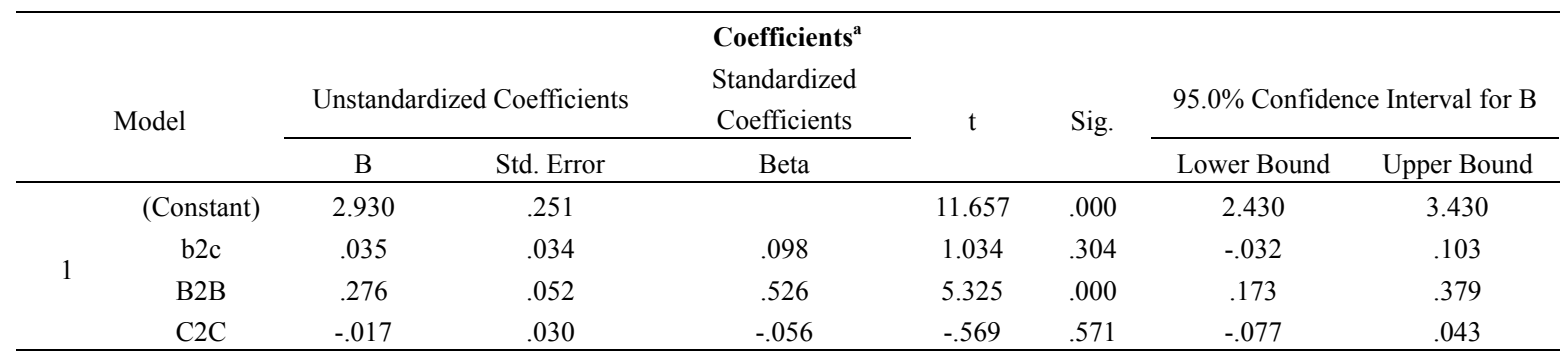

Note. a. Dependent Variable: org.performance.

The column headed unstandardized coefficient gives us first constant value which is predicted value of $\mathrm{X}$ if $\mathrm{Y}$ is 0 .In other words, if b2c score is zero then reading score is 2,930. So, b2c score goes up by 1 the reading scores are predicted to go up by 2,930.The similar case applies on b2b and c2c variables. The column headed standardized coefficient contains the Beta coefficient. The value is .098.

\section{Discussion, Conclusion, Research Implications and Future Research}

The main aim of conducting this research was help to understand the impact of E-commerce on organization performance especially banking sector of Pakistan. This study shows the existence of positive significant relationship between the Application of E-commerce and the organizational performance in the banking sector of Pakistan. It also helps the managers to understand the importance of e-commerce to improve the performance of banking sector of Pakistan. The results of this research is resembles with (Kaleem \& Ahmad, 2008) and (Chen, 2008) which reveals that e commerce is positively related with the organization performance. The limitation of this research was that the study is limited to banking sector and questionnaires are filled from the managers \& operation managers. Time and cost is another important constraint of this study. Finally, this study was limited to the non-financial aspects of organization performance, financial aspect like return on asset, return on equity, EPS and dividend payout etc are not included. This study is limited to the banking sector but it can also conduct in other sectors like Education, Telecommunication, Textile, Sports etc.

\section{References}

Bardhan, I., Krishnan, V., \& Lin, S. (2005). A Model to Measure the Business Value of Information Technology: the Case of Project and Information Work.

Bilegan, E. A. (2003). Revenue Management and E-Commerce. Management Science, 49(10), 1363-1386. http://dx.doi.org/10.1287/mnsc.49.10.1363.17316

Chad Lin, H. C. (2011). The fit between organizational B2B e-commerce policy, IT maturity and evaluation practices on B2B e-ecommerce. African Journal of Business Management, 5(5), 1983-2005.

Chen, C. C. (2008). Study on Application of E-commerce and Organizational Performance in Taiwanese Professional Sports Event Promotion Organizations. The Journal of Human Resource and Adult Learning, $4(1)$.

Chen, C. C. (2008). Study on Application of E-commerce and Organizational Performance in Taiwanese Professional Sports Event Promotion Organizations. The Journal of Human Resource and Adult Learning, $4,66-73$.

David, W., \& Nickels, O. K. (2002). The effect of organizational culture on E-Commerce adoption (pp. 276283). 
Elizabeth, E., \& Grandona, J. (2004). Electronic commerce adoption: An empirical study of small and medium US businesses (pp. 216-197).

Fang Wu, V. M. (2003). An Analysis of E-Business Adoption and its Impact on Business Performance. Journal of the Academy of Marketing Science, 31, 425-447. http://dx.doi.org/10.1177/0092070303255379

Gefen, D. (2000). E-commerce: The role of familiarity and trust. International Journal of Management Science, $725-737$.

Jui-lin Wang, F. H. H. (2003). Research on the Relationship between the Internet Usages and the Organizational Performance in the Taiwanese E-commerce Business Organizations (pp. 17-25). InSITE - Where Parallels Intersect.

Kaleem, A., \& Ahmed, S. (2008). Bankers' Perceptions of Electronic Banking in Pakistan. Journal of Internet Banking and Commerce, 13(1), 26-38.

Khawaja, A., \& Saeed, V. G. (2005). The Relationship of E-Commerce Competence to Customer Value and Firm Performance: An Empirical Investigation. Journal of Management Information Systems, 12(1), 223-256.

Lederer, Y. Z. (2003). An Instrument for Measuring the Business Benefits of E-Commerce Retailing. International Journal of Electronic Commerce, 7(3), 65-99.

Mangal, T. M. (1997). Direct and Indirect Impacts of Information Technology Applications on Productivity: A Field study. International Journal of Electronic Commerce, 1(3), 83-102.

Maroofi, F. (2011). The impact of enterprise systems on corporate performance. International Journal of Vocational and Technical Education, 3(5), 61-70.

McLean, W. H. (2004). Measuring e-Commerce Success: Applying the DeLone \& McLean Information Systems Success Model. International Journal of Electronic Commerce, 9(1), 31-47.

Moodley, S. (2001). Impact of Electronic Commerce on Small Exporting Firms in the South African Wooden Furniture Manufacturing Sector. Journal of Information Technology Impact, 2(3), 89-104.

Pedro, S. A. (2010). An empirical research of the effect of internet-based. African Journal of Business Management, 4(18), 4096-4105.

Robbins, S. P., Coulter, M., \& Vohra, N. (2009). Introduction to Management and Organizations (10th ed., pp. 2-21). Pearson Education: Publishing Prentice Hall Publications.

Singh, M. (2002). Electronic Commerce Opportunities, Challenges and Organizational Issues for Australian SMEs. Idea Group Publishing, 3.

Sutton, J. G. (1997). Organizational Performance as a Dependent Variable. Scandinavian Consortium for Organizational Research. Stanford University, 8, 698-706.

Wagner, B. A., Fillis, I., \& Johansson, U. (2003). E-business and e-supply strategy in small and medium sized businesses (SMEs). Supply Chain Management, 8, 343-354.

Yusliza, M., \& Yusoff, T. R. (2010). E-HRM: A proposed model based on technology acceptance model. African Journal of Business Management, 4(13), 3039-3045.

Zhu, K. (2005). Post-Adoption Variations in Usage and Value of E-Business by Organizations: Cross-Country Evidence from the Retail Industry. Information Systems Research. http://dx.doi.org/10.1287/isre.1050.0045

Zhu, K., \& Kenneth, L. K. (2005). Post-Adoption Variations in Usage and Value of E-Business by Organizations: Cross-Country Evidence from the Retail Industry. Information Systems Research, 16(1), 61-84.

Zott, R. A. (2001). Value Creation in E-Business. Strategic Management Journal, 22(6/7).

Zwass, V. (1996). Commerce: Structures and Issues. International Journal of Electronic Commerce, 3-23.

Zwass, V. (2003). Electronic Commerce and Organizational Innovation: Aspects and Opportunities. International Journal of Electronic Commerce, 7(3), 7-37.

\section{Copyrights}

Copyright for this article is retained by the author(s), with first publication rights granted to the journal.

This is an open-access article distributed under the terms and conditions of the Creative Commons Attribution license (http://creativecommons.org/licenses/by/3.0/). 